\title{
MISE EN SCENE DALAM FILM LAMARAN SUTRADARA MONTY TIWA
}

\author{
Muhammad Ali Mursid Alfathoni \\ Prodi Televisi dan Film \\ Fakultas Seni dan Desain Universitas Potensi Utama \\ Mhd.ali8mursid@gmail.com
}

\begin{abstract}
ABSTRAK
Penelitian ini bertujuan untuk mendeskripsi aspek mise en scene dalam film Lamaran. Film Lamaran di produksi tahun 2015 oleh Rapi Films dengan durasi 1 jam 35 menit 56 detik yang di sutradarai oleh Monty Tiwa. Di tengah popularitasnya sebagai seorang pengacara dalam menyelesaikan kasus seorang koruptor membuat Tiar mendapat ancaman pembunuhan dari seorang bos mafia. Akan tetapi, ancaman tersebut tidak membuat semangat Tiar mundur dari profesinya. Untuk menjaga keselamatan Tiar, dua orang agen mendatangkan seorang pemuda tampan yang menjadi mata-mata sekaligus pacar palsu Tiar. Keluarga Tiar protes terhadap Tiar ketika mereka mengetahui kalau Tiar berpacara dengan orang yang bukan keturunan Batak. Dalam film Lamaran terdapat unsur pembentukan film salah satunya unsur sinematik. Di dalam unsur sinematik terdapat aspek mise en scene yang saling berkesinambungan dalam film Lamaran. aspek mise en scene tersebut meliputi aspek setting (latar), aspek kostum dan tata rias, aspek pencahayaan (lighting), dan aspek pergerakan pemain. Untuk mendeskripsikan aspek mise en scene dalam film Lamaran peneliti menggunakan pendekatan deskripsi kualitatif dan semiotika.
\end{abstract}

Kata kunci: Film Lamaran, Mise en Scene, Monty Tiwa

\begin{abstract}
This study aims to describe the aspects of mise en scene in the film Application. Film Lamaran was produced in 2015 by Rapi Films with a duration of 1 hour 35 minutes 56 seconds which was directed by Monty Tiwa. In the midst of his popularity as a lawyer in resolving the case of a corruptor, Tiar got a death threat from a mob boss. However, the threat did not make Tiar's spirit withdraw from his profession. To protect Tiar's safety, two agents brought in a handsome young man who became a spy and a fake girlfriend Tiar. Tiar's family protested against Tiar when they learned that Tiar was holding a ceremony with someone who was not a Batak descendant. In the film Application there is an element of film formation, one of them is cinematic. In the cinematic elements there are aspects of mise en scenes that are mutually sustainable in the film Lamaran. the mise en scene aspects include aspects of setting (setting), aspects of costume and makeup, lighting aspects (lighting), and aspects of player movements. To describe the aspect of mise en scene in the film Application researchers used a qualitative and semiotic description approach.
\end{abstract}

Keywords: Film Lamaran, Mise en Scene, Monty Tiwa 


\section{PENDAHULUAN}

Film merupakan karya seni yang menggalami perkembangan yang begitu pesat di era perkembangan teknologi informasi pada saat ini. Film sebagai media penyampaian maupun penyebaran informasi ditengah arus perkembangan teknologi informasi mampu menjadi wadah bagi para sineas untuk memvisualisasikan berbagai fenomena sosial. Film yang diproduksi oleh para sineas senantiasa memadukan unsur gambar maupun audio sehingga film yang diproduksi akan semakin menarik untuk dinikmati. Menurut Ariani (2015: 320) film adalah serangkaian gambar yang bergerak membentuk suatu cerita yang disebut dengan movie atau video. Kemampuan gambar dalam membentuk sebuah cerita yang terdapat pada sebuah film tentu tidak lepas dari kepiawaian para sineas dalam mengolah sebuah cerita menjadi produk audio visual. Pada saat produksi sebuah film tidak pernah lepas dari unsur-unsur pembentukannya seperti unsur sinematik. Unsur sinematik merupakan teknik yang digunakan atau menjadi acuan dalam mengolah unsur naratif pada saat produksi sebuah film. Dengan kata lain, unsur sinematik merupakan aspek teknis dalam proses produksi sebuah film. Dalam unsur sinematik terdapat berbagai elemen yang saling berkesinambungan diantaranya elemen mise en scene. Mise en scene merupakan segala aspek yang ada di dalam frame yang berada di depan kamera yang akan diambil pada saat proses produksi film. menurut Pratista (2008: 61) yang dikatakan dengan mise en scene merupakan segala yang ada dan terletak di depan kamera yang akan diambil gambarnya pada saat produksi sebuah film. Mise en scene juga dapat diartikan sebagai bahasa yang berfungsi untuk menyampaikan sebuah pesan serta yang terdapat di sebuah film. Mise en scene yang terdapat di sebuah film tentu di dalamnya terdapat berbagai tanda maupun penanda. Oleh karena itu, penulis tertarik untuk mendeskripsikan tanda dan penanda dalam sebuah film melalui mise en scene dengan pendekatan kualitatif.

Adapun film yang menjadi objek kajian dalam penelitian ini adalah film Lamaran sutradara Monty Tiwa. Film Lamaran di produksi oleh Rapi Films pada tahun 2015 dengan durasi 1 jam 35 menit 56 detik. Film Lamaran menceritakan seorang pengacara berdarah dan bersuku Batak yang bernama Tiar Sarigar. Tiar Sarigar bertugas membela seorang koruptor yang bernama Basuki. Keberanian yang di miliki oleh Tiar sebagai seorang pengacara membuat popularitasnya semakin meningkat. Di tengah popularitasnya sebagai seorang pengacara Tiar mendapat ancaman dan ingin di bunuh oleh seorang bos mafia yang bernama Arif Rupawan yang senantiasa berusaha menutupi keterlibatannya. Arif Rupawan yang menjadi ancaman terhadap keselamatan Tiar membuat dua orang agen Ari dan Sasha berusaha penuh untuk menjaga keselamatannya dari ancaman Arif Rupawan. Berbagai cara digunakan Ari dan Sasha untuk melindungi Tiar termasuk mendatangkan seorang laki-laki yang berwajah tampan, lugu serta polos yang bersuku Sunda. Lelaki tampan tersebut bernama Aan. Aan ditugaskan menjadi seorang mata-mata serta menjadi pacar palsu Tiar. Keluarga Tiar memprotes serta tidak menyetujui kalu Tiar pacaran dengan Aan yang tidak keturunan dan bersuku asli Batak. Akan tetapi, Ari dan Sasha tetap berusaha dan memberikan motivasi serta dorongan kepda Aan untuk berusaha mengambil hati keluarga besar Sarigar dengan membeli marga Batak. Akan tetapi, keadaan tidak berjalan dengan mulus karena Meja sepupu Tiar membalikkan serta memanipulasi keadaan untuk mengambil keuntungan pribadi dari pembelian marga yang akan dilakukan oleh Aan. Bu Sarigar memikirkan segala cara agar Tiar dan Aan tidak berjodoh. Berbagai cara dilakukan olehnya termasuk berusaha menjodohkan Tiar dengan lelaki yang bersuku Batak bernama Raymond. Usaha yang dilakukan oleh Bu Sarigar tidak membuahkan hasil. Hal tersebut dikarenakan Tiar lebih memilih Aan yang lugu dan polos. Konflik semakin menimpa Tiar atas keputusannya memilih Aan. Melihat keputusan Tiar yang tetap memilih Aan membuat Bu Sarigar dan Bu Euis merestui hubungan mereka walaupun antara adat 
Sunda dan Batak terdapat titik perbedaan. Di sisi lain, bos mafia yang tidak bias menerima kekalahannya tetap berusaha untuk menghabisi nyawa Tiar ketika Tiar dan Aan melangsungkan resepsi pernikahan.

Mise en scene yang terdapat pada film Lamaran tentu memiliki tujuan maupun makna yang terkandung di dalamnya. Film Lamaran sebagai sebuah produk karya seni yang diangkat berdasarkan fenomena sosial budaya tentu terdapat berbagai sistem tanda maupun penanda yang masuk ke dalam ranah kajian semiotika. Semiotika merupakan ilmu tentang tanda dan penanda, jadi dapat dikatakan semiotika merupakan suatu bidang keilmuan yang mampu mengungkapkan segala bentuk informasi melalui tanda dan penanda yang terdapat di dalam sebuah objek seperti halnya film. melalui ranah kajian semiotika tujuan maupun makna yang terdapat pada struktur mise en scene dalam film Lamaran dapat diungkapkan.

\section{II.STUDI LITERATUR}

Adapun yang menjadi rujukan dalam penulisan penelitian ini adalah hasil penelitian Citra Ratna Amelia tahun 2015 yang berbentuk tesis yang berjudul " Mise En Scene Jagongan Sar Gedhe, Sebuah Kajian Semiotika”. Tesis Citra Ratna Amelia berisikan tentang sebuah program jurnalistik dengan format hard interview. Program Jagongan Sar Gedhe mengusungkan kemasan yang berbeda dengan program jurnalistik lainnya. Kemasan dalam program Jagongan Sar Gedhe disajikan melalui mise en scene sehingga program Jagongan Sar Gedhe menjadi sebuah program fenomena bahasa dan pertandaan yang masuk dalam ranah kajian semiotika yang sangat menarik untuk diteliti lebih lanjut. Dalam penelitian ini Citra Ratna Gedhe menggunakan pendekatan semiotik Roland Barthes. Citra Sar Gedhe melakukan pendekatan terhadap denotative dan konotatif terhadap deskripsi mise en scene pada program Jagongan Sar Gedhe. Melalui deskripsi mise en scene setiap makna dan latar belakang penciptaan program Jagongan Sar Gedhe dapat terungkap.

Selanjutnya, yang menjadi rujukan peneliti adalah hasil penelitian Naafi Nur Rohma tahun 2017 yang berbentuk jurnal ilmiah dengan judul "Estetika Formalis Film Pohon Penghujan Sutradara Andra Fembrianto". Artikel ini berisikan tentang bentuk estetika formalis dari film pohon penghujan sehingga dapat diketahui makna yang terdapat di balik film penghujan. Analisis yang digunakan oleh Naafi Nur Rohma dalam mengkaji film pohon penghujan adalah analisis interpretasi pendekatan estetika formalis Sergei Eisenstein, yaitu mise en scene, sinematografi, montase, dan suara. Hasil yang ditemukan oleh Naafi Nur Rohma dalam penelitiannya terdapat makna di balik empat adegan yang dipilih berdasarkan tingkatan dramatik

\section{PEMBAHASAN \\ III.1. Mise En Scene}

Dalam film mise en scene memiliki arti "putting in the scene" yang berasal dari kata Perancis. Mise en scene merupakan salah satu unsur yang penting yang terdapat dalam elemen sinematik yang terdapat dalam film. Unsur tersebut sangat penting diperhatikan agar film yang di produksi dapat memberikan kesan dramatis di setiap alur cerita. Setiap 
film yang di produksi para sineas tentu terlebih dahulu memikirkan secara matang mise en scene yang ingin diterapkan ke dalam film yang akan di produksi. Film-film yang berlatar budaya lokal tentu memiliki keunikan tersendiri dalam penerapan mise en scene ke dalam film yang akan di produksi seperti halnya film Lamaran sutradara Monty Tiwa. Mise en scene sebagai unsur pendukung yang memegang peran penting dalam sebuah film akan membawa kekuatan tersendiri disetiap aspek cerita di dalam sebuah film. Mise en scene yang terdapat dalam film terdiri dari empat aspek seperti bagan dibawah ini:

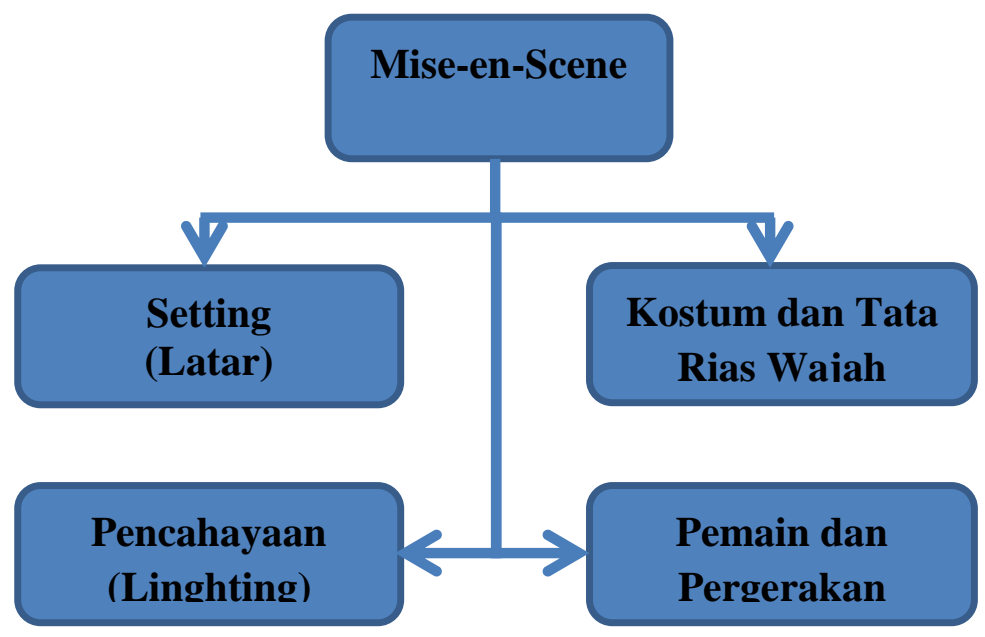

Gambar 1. Aspek Mise-en-scene (Sumber: Pratista, 2008)

Setting (latar) dalam stuktur mise en scene berkaitan dengan semua properti yang terdapat di dalam sebuah film. Properti yang dimaksud dapat berupa rumah, pintu, kursi, gitar, lampu dan sebagainya. Dalam film setting yang digunakan senantiasa dibuat dengan senyata mungkin agar sesuai dengan konteks yang terdapat dalam alur cerita dalam film yang di produksi. Adapun yang disebut dengan kostum dan tata rias wajah dalam sebuah film merupakan semua unsur yang dipakai oleh para aktor disaat proses akting pada saat pembuatan film beserta semua aksesoris yang dipakainya. Kostum dan tata rias yang dipakai oleh para aktor berfungsi untuk mencerminkan konteks yang terdapat dalam alur cerita film. Menurut Pratista (2008: 71) kostum dalam sebuah film memiliki fungsi sebagai penunjuk ruang dan waktu, status sosial, kepribadian para aktor, sedangkan warna kostum yang digunakan para aktor menandakan simbol serta motif penggerak cerita. Sedangkan pencahayaan merupakan unsur dasar yang sangat berperan penting dalam produksi sebuah film. Tanpa cahaya seluruh unsur yang dipadukan dalam pembuatan film tidak akan terlihat bahkan tidak memiliki wujud. Cahaya dalam pembuatan film berfungsi untuk memanipulasi setiap gambar yang ada disetiap adegan film yang menyangkut kualitas, arah, sumber, dan warna. Pencahayaan dalam pembuatan film sangat berperan penting dalam membangun suasana maupun mood yang terdapat di dalam film. Selanjutnya, aspek yang harus diperhatikan oleh seorang sineas adalah para aktor dan pergerakannya. Aspek tersebut merupakan unsur yang akan memotivasi setiap unsur naratif yang terdapat di dalam sebuah film. Seorang aktor sangat di tuntut untuk mampu melakukan pergerakan yang akan membangun aspek dramatis disetiap alur cerita sehingga pesan-pesan yang ada bisa tersampaikan dengan baik. 


\section{III.2. Semiotika}

Menurut Sobur (2006: 14-15) bahwa semiotika merupakan suatu ilmu yang digunakan untuk menganalisa dan mengkaji tanda. Semiotika secara estimologis berasal dari bahasa yunani "Semeion" yang memiliki arti tanda. Tanda dapat diartikan sebagai suatu konvensi sosial yang sudah terbangun sebelumnya. Semiotika mampu mengidentifikasi sederetan objek, peristiwa, kebudayaan sosial sebagai sitem tanda. Tanda menurut Roland Barthes tidak bisa lepas dari bahasa. Barthes menyatakan bahwa bahasa adalah sebuah sistem tanda yang mencerminkan asumsi-asumsi dari suatu masyarakat tertentu dalam waktu tertentu (Sobur, 2003:63). Dalam film Lamaran tentu terdapat berbagai sistem tanda yang memiliki makna tertentu yang tercermin disetiap aspek mise en scene yang ada pada film Lamaran. Oleh karena itu, peneliti menggunakan semiotika untuk mengungkapkan makna yang terdapat disetiap aspek mise en scene dalam film Lamaran sutradara Monty Tiwa. Dalam kajian semiotika asumsi yang paling mendasar bahwa segala sesuatu merupakan tanda yag dapat menimbulkan arti tertentu.

Pada dasarnya, konsep utama semiotika, mencangkup tiga elemen dasar yang digunakan untuk melakukan interpretasi tanda, yaitu:

1. Tanda (sign), adalah yang memimpin pemahaman objek kepada subyek. Tanda selalu menunjukkan kepada suatu hal yang nyata, seperti benda, kejadian, tulisan, peristiwa dan sebagainya. Tanda adalah arti yang statis, lugas, umum, dan objektif.

2. Lambang (symbol), adalah keadaan yang memimpin pemahaman subyek kepada objek. Pemahaman masalah lambang akan mencakup penanda (signifier), dan petanda (signified). Penanda adalah yang menandai sesuatu yang tidak seorang pun manusia yang sanggup berhubungan dengan realitas kecuali dengan perantara bernacam tanda.

3. Isyarat (signal), adalah suatu hal atau keadaan yang diberikan oleh subjek kepada objek (Amelia, $2015: 40$ ).

Untuk mendeskripsikan makna yang terdapat dalam aspek mise en scene peneliti menggunakan teori Semiotika Ferdinan de Saussure. Saussure berpendapat bahwa bahasa merupakan sistem tanda yang tersusun dari dua bagian, yaitu penanda dan petanda (Sobur, 2006: 46). Menurut Barker (2004:32) semiotika mampu mengekplorasikan sebuah makna yang terbangun oleh teks yang diperoleh dari sistem penataan tanda dengan menggunakan teknik kode-kode budaya. Dari pernyataan tersebut dapat disimpulkan bahwa setiap yang ada dalam kehidupan manusia merupakan sistem tanda yang memiliki makna di dalamnya.

\section{III.3. Mise En Scene Pada Film Lamaran Sutradara Monty Tiwa III.3.1. Aspek Setting (Latar)}

Table 1. Aspek Setting (latar) Ketika Tiar diberi Tanggung Jawab Memegang Kasus Pak Basuki

\begin{tabular}{|l|l|}
\hline Visual & Teks/Dialog/Suara \\
\hline
\end{tabular}




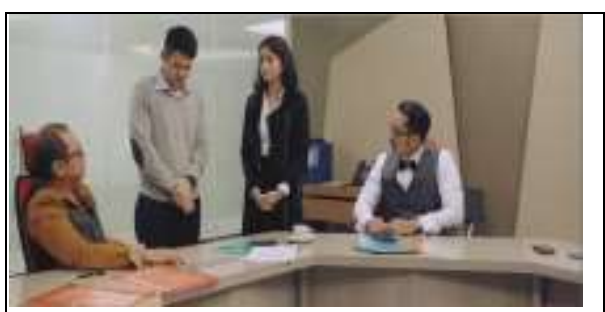

Partner Hukum : Karena kau sudah tak sabar mau cepat-cepat mati. Kau saja yang megang kasus ini.

Tiar : Hhh...Siap Pak.

Tulang : ehh. Tapi Tiar, please untuk kali ini aj you bantu I.

Gambar 1. Adegan Tiar di beri Tanggung Jawab Memegang Kasus Basuki

(Sumber: Capture film Lamaran, 2015)

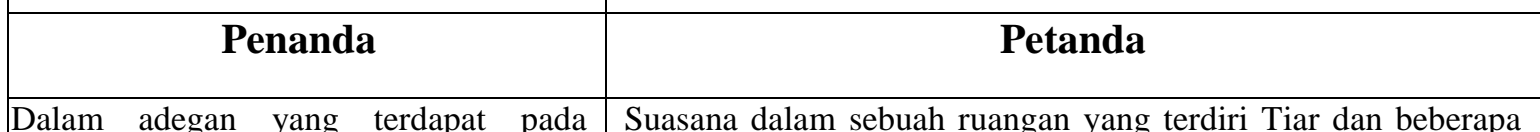

gambar 1 terlihat Tiar berada dalam sebuah ruangan. Dalam ruangan tersebut terdapat beberapa orang. Dialog adegan yang terdapat pada gambar 1 mencerminkan bahwa Tiar dikatakan tidak sabar untuk cepat mati. Tulang Tiar terlihat kurang optimis memberikan tanggung jawab kepada Tiar hal tersebut terlihat dari kata-kata yang diungkap Tulangnya.s orang di dalamnya menunjukkan bahwa Tiar sedang berada disebuah ruangan kantor. Dialog yang terjadi antara Partner hukum dengan Tiar menunjukkan bahwa Tiar orang yang berani dan optimis dalam menghadapi suatu masalah yang berkaitan dengan ranah hukum. Ketika mendengar kesempatan yang diberikan oleh Tulangnya membuat Tiar semakin yakin kalau dia mampu menyelesaikan kasus yang menimpa pak Basuki.

Adegan yang terdapat pada gambar 1 film Lamaran yang berlatar sebuah ruangan kantor. Dalam adengan tersebut menunjukan bahwa latar waktu yang digunakan oleh sutradara dalam mengambil scene tersebut dilakukan pada waktu pagi hari. Hal tersebut tercermin dari semangat, mimik wajah dari para aktor maupun aktris dalam adegan tersebut. Adengan yang terdapat pada scene tersebut juga menunjukkan bahwa suasana yang terjadi dalam ruangan kantor tersebut menunjukkan suasana yang tegang. Suasana tegang tersebut terjadi akibat keberanian Tiar dalam membela kasus yang korupsi yang menimpa pak Basuki. Selain itu, dalam adegan tersebut juga mencerminkan latar sosial dari seorang pengacara pemula yang memiliki jiwa sosial yang tinggi dan optimis dalam menyelesaikan kasus yang menimpa korupsi yang menimpa pak Basuki.

Sumber: Ali Mursid. 2015.

Table 2. Aspek Setting (latar) Ketika Arif Rupawan Memberi Tugas Untuk Meneror Tiar

\begin{tabular}{|c|l|}
\hline \multicolumn{1}{|c|}{ Visual } & \multicolumn{1}{c|}{ Teks/Dialog/Suara } \\
\hline & $\begin{array}{l}\text { Arif Rupawan : Kamu kerjanya nggak becus. Itu kenapa } \\
\text { pengacara bau kencur muncul trus di TV. Bawa-bawa nama } \\
\text { saya lagi. Kamu tahu nggak kesalahan kamu apa ? }\end{array}$ \\
Ajudan : Nggak tahu papi. \\
$\begin{array}{c}\text { Ajudanny Untuk Meneror Tiar } \\
\text { (Sumber: Capture film Lamaran, 2015) }\end{array}$ & $\begin{array}{l}\text { Arif Rupawan : Karen kamu nggak becus. Mulai sekarang } \\
\text { kamu ikutin dia, kalau perlu kamu teror. }\end{array}$ \\
& Arif Rupawan : Kali ini yang benar. \\
\hline Penanda & Ajudan: Siap papi. \\
\hline Dalam adegan yang terdapat pada gambar & Dalam adegan yang terdapat pada gambar 2 terlihat Arif \\
\hline
\end{tabular}


2 bahwa Arif Rupawan dan ajudannya sedang berada di dalam sebuah ruangan. Suasan ruangan yang kondusif terlihat Arif Rupawan mengajukan beberapa pertanyaan kepada ajudannya. Dari dialog terlihat Arif Rupawan marah kepada ajudannya.
Rupawan sangat serius bertanya kepada ajudannya yang didukung dengan latar suasana yang agak mencekap. Dalam latar yang terdapat pada gambar 2 terlihat bahwa Arif Rupawan sangat kecewa dengan ketidakbecusan ajudannya dalam menjalankan tugas. Arif Rupawan menugaskan supaya ajudannya mengikuti dan meneror Tiar yang bertujuan untuk mengendorkan semangat dan keberanian Tiar dalam menangani kasus Pak Basuki.

Suasana latar ruangan yang di dekorasi agak gelap mencerminkan bahwa keberadaan Tiar dan keberanian Tiar memegang kasus pak Basuki merupakan sebuah ancaman bagi Arif Rupawan. Suasana latar tersebut mencerminkan bahwa kehidupan seorang mafia senantiasa serius dan berani dalam bertindak dan meneror orang-orang yang ikut campur dalam urusan mereka.

Sumber: Ali Mursid. 2015.

Table 3. Aspek Setting (latar) Ketika Ari dan Sasha Mendatangkan Aan Untuk Menjadi Pacar Pura-pura Tiar

\begin{tabular}{|c|c|}
\hline Visual & Teks/Dialog/Suara \\
\hline $\begin{array}{l}\text { Gambar 3. Adegan Arif Ari dan Sasha } \\
\text { Mengenalkan Aan dan Tiar } \\
\text { (Sumber: Capture film Lamaran, 2015) }\end{array}$ & $\begin{array}{l}\text { Ari : Kita memang culik kau, tapi... } \\
\text { Sasha : Demi kebaikan. } \\
\text { Ari : ia, tujuan yang mulia. } \\
\text { Sasha: Amal itu tergantung niat. } \\
\text { Ari: Pengorbanan. } \\
\text { Sasha : Pengorbanan membuka pintu keikhlasan. } \\
\text { Aan: Kenapa mesti saya atuh... } \\
\text { Ari : Karena misi ini sangat penting dalam menentukan arah } \\
\text { bangsa dan Negara ini. Kamu harus mendekati seseorang } \\
\text { karena sosok ini sangat berperan penting untuk takdir bangsa } \\
\text { dan Negara ini dari sabang sampai merauke. } \\
\text { Aan: Tuhan } \\
\text { Ari: Kita butuh orang yang dekat dengan kamu. Dan alasan } \\
\text { yang memungkinkan itu adalah pacar kamu. } \\
\text { Ari: Salah satu ciptaannya. } \\
\text { Ari: Nona Tiar. Perkenalkan itu Aan. }\end{array}$ \\
\hline Penanda & Petanda \\
\hline $\begin{array}{l}\text { Dalam adegan yang terdapat pada gambar } \\
3 \text { terlihat setting dalam sebuah bioskop. } \\
\text { Dalam setting tersebut mengambarkan }\end{array}$ & $\begin{array}{l}\text { Dalam adegan tersebut menunjukkan bahwa latar suasana } \\
\text { sebuah bioskop merupakan sebuah tempat yang romantis bagi } \\
\text { orang yang menjalin cinta. Hal tersebut tercermin dari dialog }\end{array}$ \\
\hline
\end{tabular}




$\begin{aligned} & \text { suasana latar yang terlihat gelap yang } \\ & \text { menunjukkan suasana bioskop. Suasana }\end{aligned}$
Tiar terlihat kaget begitu juga dengan
$\begin{aligned} & \text { Aan. Akan tetapi Ari terlihat menjelaskan } \\ & \text { berpacaran. Dalam scene tersebut juga menunjukkan bahwa } \\ & \text { sesuatu. Dari dialog terlihat Aan di } \\ & \text { datangkan Ari dan Sasha unan Tiar merupakan faktor yang sangat penting dan } \\ & \text { melindungi Tiar dari ancaman mafia. }\end{aligned}$

Sumber: Ali Mursid. 2015.

Table 4. Aspek Setting (latar) Ketika Keluarga Tiar Protes Akan

Hubungan Aan Tiar dan Sepupu Tiar Mengambil Keuntungan dari Aan yang Ingin Mengambil Marga

\begin{tabular}{|c|c|}
\hline Visual & Teks/Dialog/Suara \\
\hline $\begin{array}{l}\text { Gambar 5. Adegan Sepupu Tiar Mengambil } \\
\text { Kesempatan Ketika Aan mau Membeli Marga } \\
\text { (Sumber: Capture film Lamaran, 2015) }\end{array}$ & $\begin{array}{l}\text { Bapak Tiar : Aha Marga mu...? } \\
\text { Aan: Saya Aan. } \\
\text { Sepupu Tiar : Alamat bukan Batak kau...? } \\
\text { Ari : Bung santai...Aan ini memang bukan orang Batak } \\
\text { tapi dia ini pacarnya Tiar. } \\
\text { Keluarga Tiar : aaahhhh.....?? } \\
\qquad \text { @epupu Tiar : Bodat, kau pikir dapat marga itu gampang. } \\
\text { Ari : makanya kami datangi kau ini. } \\
\text { Sepupu Tiar : Marga itu tidak semudah nenek moyang } \\
\text { kau. } \\
\text { Ari: Intinya, bias tidak? } \\
\text { Sepupu Tiar : Kau selow kawan, gampang itu. } 150 \text { juta. } \\
\text { tenda, tupak, arsik potong babi. }\end{array}$ \\
\hline Penanda & Petanda \\
\hline
\end{tabular}


Pada gambar 4 setting diambil di dalam ruangan disebuah rumah milik kedua orang tua Tiar. Suasana latar di dalam rumah tersebut dikemas dengan adegan yang sedikit menegangkan. Dari dialog latar suasana menunjukkan bahwa keluarga Tiar kaget dengan kehadiran Aan dan mereka bertanya Aan suku dan marga apa. Akan tetapi, pada adegan yang terdapat pada gambar 5 terlihat setting di sebuah bengkel. Suasana latar terlihat agak kaku.
Setting dalam adegan yang terlihat pada gambar 4 menunjukkan kondisi sebuah rumah Tiar ketika para keluarga sedang berkumpul. Keluarga Tiar berkumpul untuk merayakan keberhasilan Tiar menjadi seorang pengacara. Tujuan keluarga Tiar menanyakan marga Tiar agar keluarga Tiar tahu Aan suku apa dan memiliki marga apa. Keinginan Aan agar hubungan mereka tetap berlanjut sehingga membuat Aan berusaha membeli marga batak. Tujuan Aan membeli marga tersebut agar hubungannya disetujui oleh keluarga Tiar.

Setting yang tercermin dari adegan yang terdapat pada gambar 4 dan 5 menunjukkan bahwa suasana rumah orang Tiar sedang ada acara keluarga. Kebiasaan orang yang bersuku Batak ketika ada salah satu anak keturunan mereka yang berhasil mereka akan mengadakan acara syukuran. Setting sebuah bengkel yang terdapat dalam film Lamaran ketika Aan ingin membeli marga menunjukkan bahwa orang Batak yang hidup diperantaun harus senantiasa bekerja keras agar menjadi orang yang berhasil. Keinginan Aan mendapatkan marga menunjukkan latar sosial yang harus dimiliki setiap orang yang berbeda suku. Ketika Aan ingin memiliki marga di setting oleh sutradara penuh dengan rintangan. Hal tersebut bertujuan bahwa marga bagi orang Batak merupakan suatu hal yang sacral dan tidak bias sembarangan di miliki. Jika diberikan kepada orang yang bukan Batak maka harus mengikuti prosesi sesuai aturan adat Batak.

Sumber: Ali Mursid. 2015.

Table 5. Aspek Setting (latar) Ketika Raymond dan Tiar

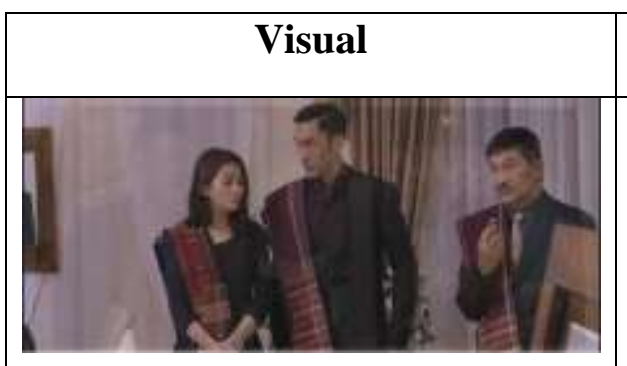

Gambar 6. Adegan Raymond dan Tiar (Sumber: Capture film Lamaran, 2015)

\begin{tabular}{|l|l|}
\hline \multicolumn{1}{|c|}{ Penanda } & \multicolumn{1}{|c|}{ Petanda } \\
\hline $\begin{array}{l}\text { Pada gambar 6 terlihat setting dalam } \\
\text { sebuah rumah. Pada gambar 6 juga } \\
\text { menunjukkan setting sosial suatu } \\
\text { suku yang ada di Indonesia. Dari } \\
\text { dialog disetting dengan nada yang } \\
\text { agak rendah. }\end{array}$ & $\begin{array}{l}\text { Adegan pada gambar 6 menunjukkan bahwa setting } \\
\text { Batak ketika ada sebuah hajatan senantiasa } \\
\text { mengkedepankan adat budaya mereka. Dialog yang } \\
\text { terdapat dalam adegan tersebut menunjukkan bahwa } \\
\text { ibu Tiar sangat berharap kalau Tiar berjodoh dengan } \\
\text { orang yang bersuku Batak. }\end{array}$ \\
\hline
\end{tabular}

Adegan yang tercermin pada gambar 6 menunjukkan bahwa setting yang diambil dalam rumah orang tua Tiar. Dalam kehidupan masyarakat Batak jika seorang anak maupun keturunan mereka berhasil dalam suatu bidang senantiasa diadakan sebuah syukuran. Dalam kehidupan orang Batak harapan seorang orang tua senantiasa berharap anak perempuannya berjodoh dengan seorang yang dianggap mapan dan memiliki darah dan keturunan yang sama. 
Table 6. Aspek Setting (latar) Ketika Tiar dan Aan Repsi Pernikahan dan Ingin dibunuh Oleh Arif Rupawan

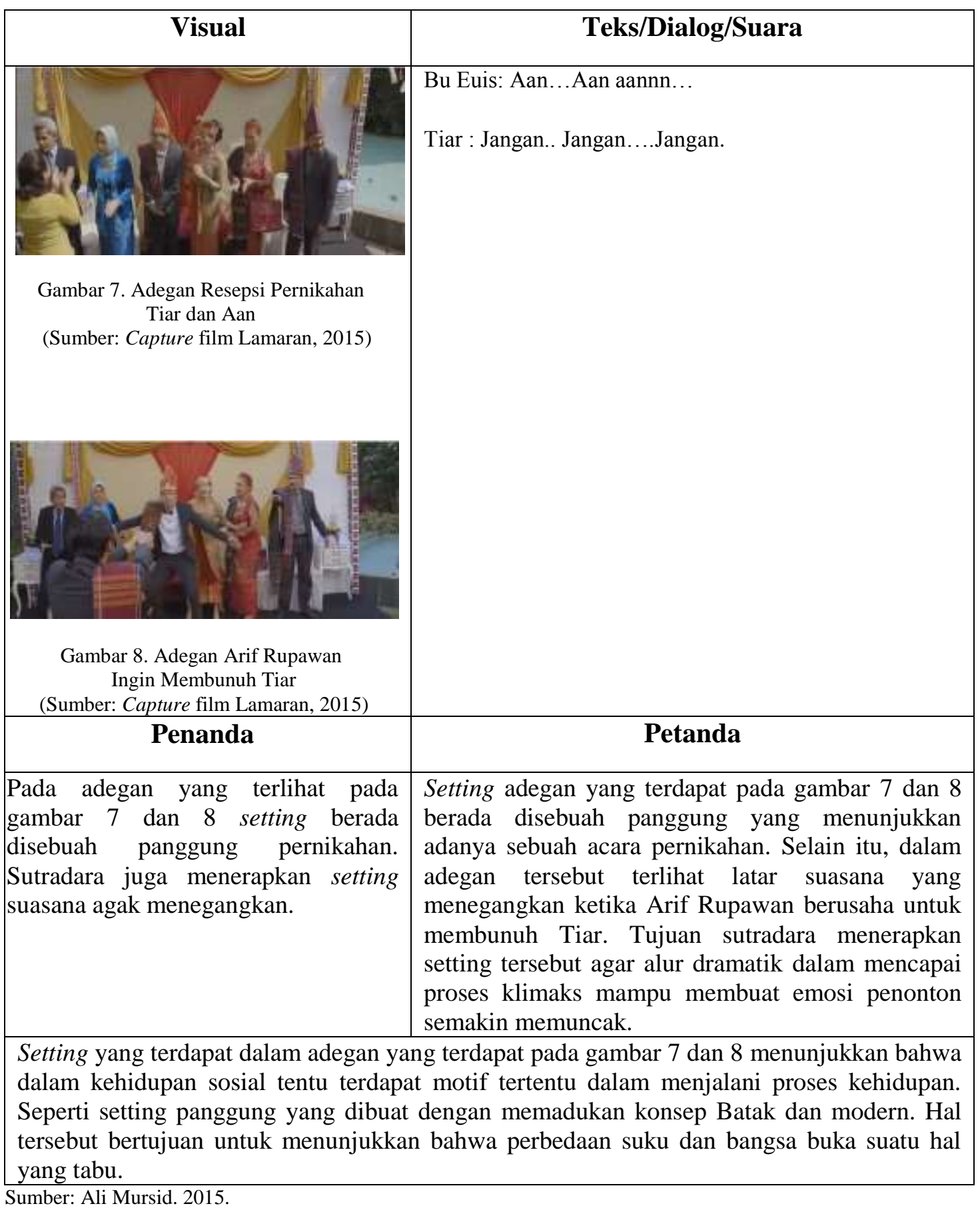




\section{III.3.2. Aspek Kostum dan Tata Rias}

Table 7. Aspek Kostum dan Tata Rias dalam Film Lamaran

\begin{tabular}{|c|c|}
\hline Visual & Teks/Dialog/Suara \\
\hline $\begin{array}{c}\text { Gambar 8. Kostum Tiar dan Para Pegawai } \\
\text { di Kantor } \\
\text { (Sumber: Capture film Lamaran, 2015) }\end{array}$ & \\
\hline
\end{tabular}

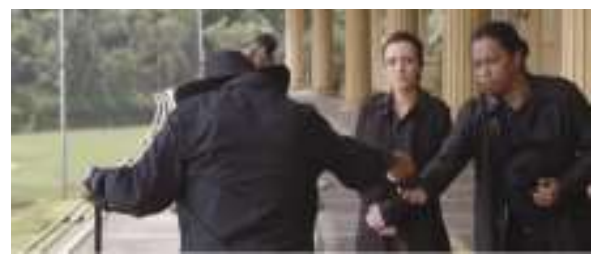

Bos Agen Rahasia : Coba lihat itu, jadi Tiar itu sangat penting. Jadi jangan lepas 1 menit pun dari pengawasan. Karena kasus ini bernuansa politik.

Gambar 9. Kostum Agen Rahazia (Sumber: Capture film Lamaran, 2015)

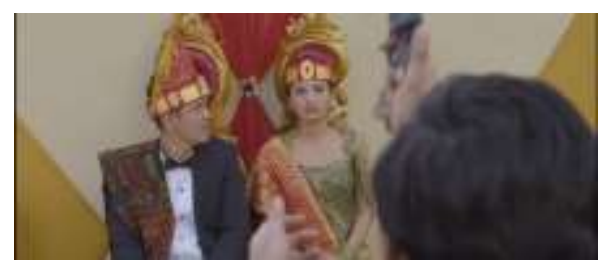

Gambar 10. Kostum Aan dan Tiar Ketika Resepsi Pernikahan

(Sumber: Capture film Lamaran, 2015)

\begin{tabular}{|c|}
\hline \multicolumn{2}{|c|}{ Penanda } \\
\hline Pada gambar 8 Tiar menggunakan
\end{tabular}

kostum berwarna putih dan stelan blezer abu muda. Para wartawan memeakai kostum berwarna hitam dan baju kemeja kotak-kotak merah dan biru. Pada gambar 9 para agen rahasia memakai kostum warna hitam. Akan tetapi, pada gambar 10 Aan dan Tiar memakai kostum kas pengantin salah satu suku Batak. Selain itu, Tiar, Aan, agen rahasia dan wartwan dilengkapi dengan berbagai atribut. Untuk make up dalam film Lamaran tidak memakai efek khusus sehingga terlihat lebih natural.

Berbagai bentuk kostum yang terdapat dalam film Lamaran mencerminkan keberagaman yang ada di Indonesia. Dalam film Lamaran mencerminkan suku Sunda dan Batak. Sehingga sutradara mengusung konsep yang sesuai dengan kostum yang mencerminkan adanya dua suku yang diperan dalam film Lamaran. Seperti hal nya kostum yang bernuansa 
Batak. Sortali yang digunakan Tiar yang terbuat dari tembaga yang disepuh dengan emas. Sortali tersebut berfungsi sebagai mahkota bagi pengantin perempuan. Selendang ulos yang Tiar dan Aan gunakan sebagai kostum merupakan ciri khas masyarakat bersuku Batak. Jenis ulos yang mereka gunakan merupakan jenis ulos Batak Toba.

Sumber: Ali Mursid. 2015.

\section{III.3.3. Aspek Pencahayaan(lighting)}

Table 8. Aspek Pencahayaan(lighting) dalam Film Lamaran

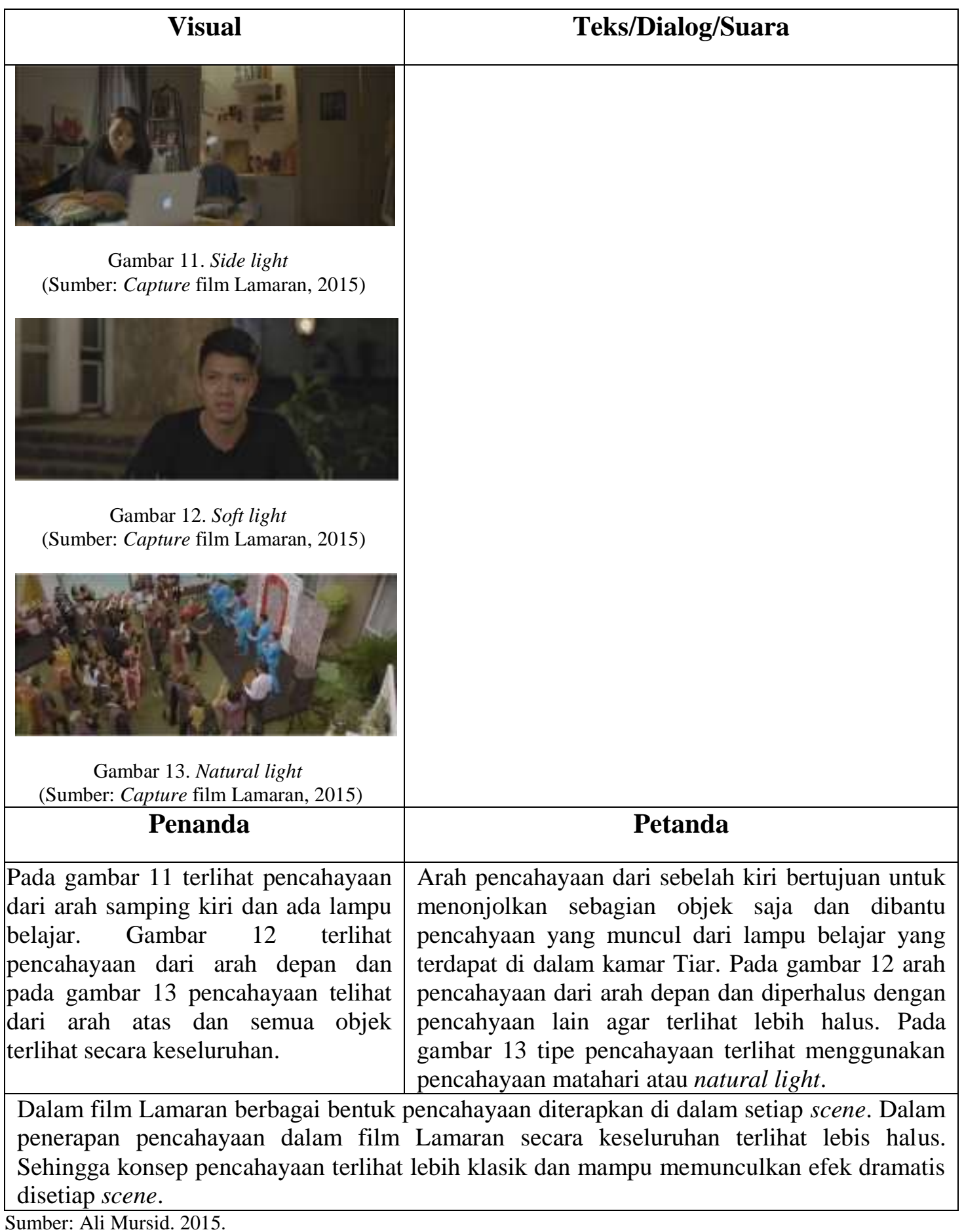




\section{III.3.4. Aspek Pergerakan Pemain}

Table 9. Aspek Pergerakan Pemain dalam Film Lamaran

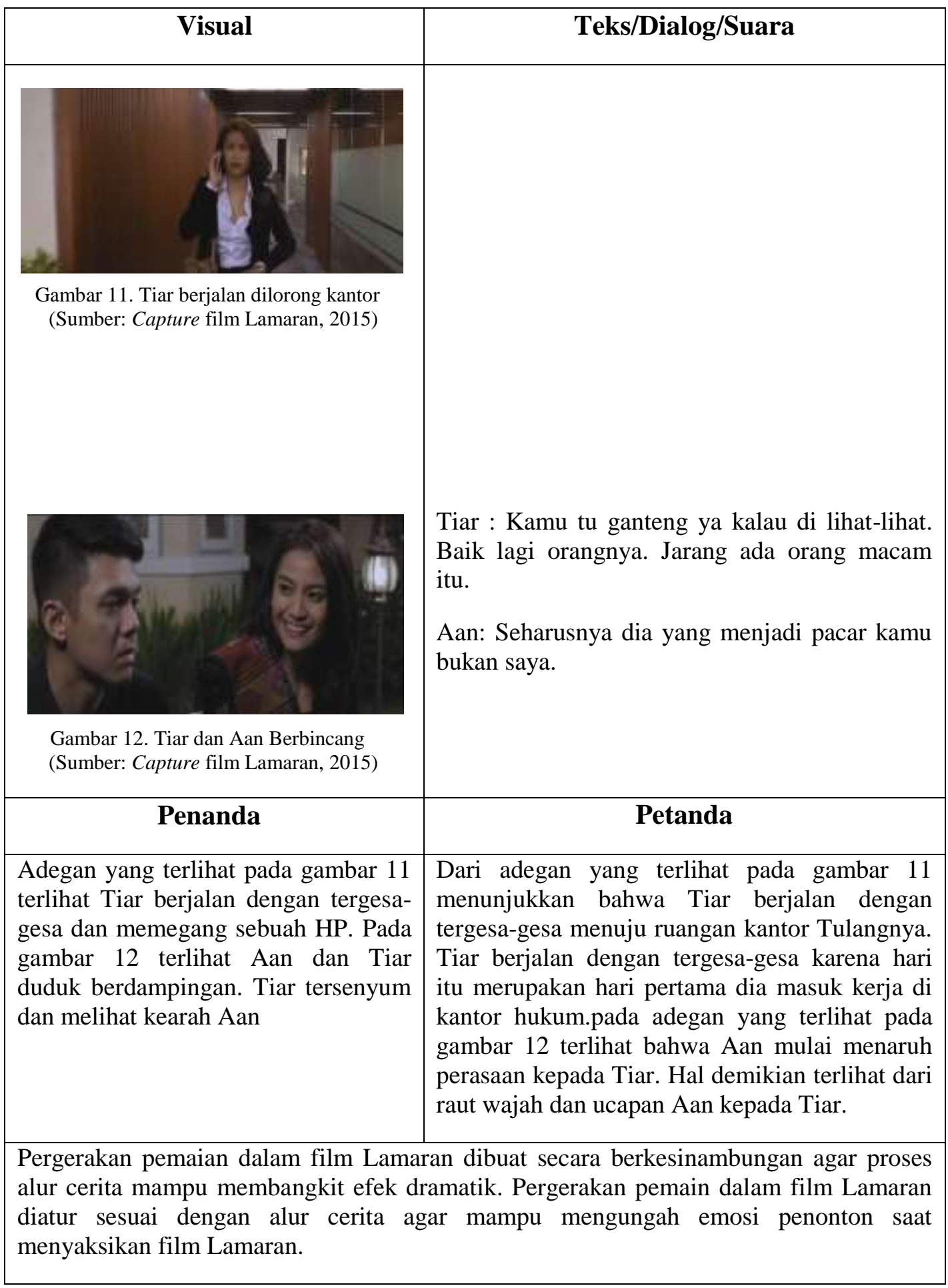

Sumber: Ali Mursid. 2015.

\section{KESIMPULAN}

Film Lamaran merupakan film yang bergenre komedi yang menceritakan kehidupan seorang pengacara berdarah Batak. Dalam film Lamaran tentu terdapat unsur Mise en scene. Mise en scene dalam film Lamaran terdiri dari aspek setting (latar), kostum dan 
tata rias, pencahayaan (lighting) dan pergerakan pemain. Aspek setting (latar) dalam film Lamaran meliputi di dalam ruangan dan diluar ruangan. Aspek kostum dan tata rias dalam film Lamaran dibuat dengan konsep yang klasik sehingga mampu mencerminkan sosial budaya lokal daerah. Aspek Pencahayaan(lighting) yang diterapkan dalam film Lamaran terlihat lebih halus dan tidak mencolok. Film Lamaran menerapkan tipe pencahayaan (lighting) side, soft, natural. Kemampuan sutradara dalam memadukan setiap unsur Mise en scene dalam film Lamaran mampu mengungah dan membangkitkan emosi penonton.

\section{DAFTAR PUSAKA}

[1] Ariani, Meldina. 2015, "Representasi Kecantikan Wanita dalam Film 200 Punds Beauty Karya Kim Young Hwa". Dalam eJurnal Ilmu Komunikasi, Vol. 3 No.4 Hal.320

[2] Amelia, Citra Ratna. 2015. "Mise En Scene Program Jagongan Sar Gedhe, Sebuah Kajian Semiotika". Tesis. Program Pascasarjana Institut Seni Indonesia. Surakarta.

[3] Barker, Chris. 2004. 2010. Culture Studies. Yogyakarta: Kreasi Wacana.

[4] Himawan, Pratista. 2008. Memahami Film, Yogyakarta: Homerian Pustaka.

[5] Rohma, Naafi Nur. 2017. "Estetika Formalis Film Pohon Penghujan Sutradara Andra Fembriarto". dalam jurnal Rekam, Vol. 13 No.1 ISI Surakarta.

[6] Sobur, Alex. 2006. Analisis Teks Media, Bandung: Remaja Resdakarya.

[7] Sobur, Alex. 2003. Semiotika Komunikasi, Bandung: Rosdakarya. 